\title{
Um marcador químico de fácil detecção para a própolis de Alecrim-do-Campo (Baccharis dracunculifolia)
}

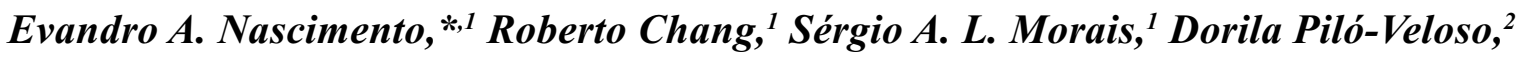 \\ Débora Costa Reis ${ }^{2}$
}

\author{
${ }^{1}$ Instituto de Química, Universidade Federal de Uberlândia, Av. João Naves de Ávila, 2121, \\ 38408-100 Uberlândia-MG, Brasil \\ ${ }^{2}$ Departamento de Química, Universidade Federal de Minas Gerais, Av. Antônio Carlos, 6627, 31270-901 \\ Belo Horizonte-MG, Brasil,
}

\begin{abstract}
RESUMO: O presente trabalho apresenta um marcador químico (MQ) volátil, de fácil detecção por cromatografia gasosa, para a própolis do alecrim-do-campo (Baccharis dracunculifolia). Trata-se do composto volátil mais abundante no extrato em diclorometano de própolis verdes dessa planta, mas que aparece, também, em diferentes concentrações, em extratos de diclorometano de própolis marrom, preta, vermelha e amarela, provenientes de regiões que contêm Baccharis dracunculifolia. O MQ está presente no extrato dos ápices vegetativos de alecrim em concentração significativa, mas sua concentração na folha de alecrim é baixa. Própolis de regiões sem alecrim não possuem o MQ. Este composto foi isolado recentemente e se trata do 3-prenilcinamato de alila. Amostras comerciais de extratos etanólicos de própolis verdes foram analisadas e a de primeira qualidade, tipo exportação, apresentou maior concentração de MQ. Tal descoberta facilita o rápido controle de qualidade de extratos etanólicos de própolis verdes.
\end{abstract}

Unitermos: Baccharis dracunculifolia, Asteraceae, própolis, marcador químico.

\begin{abstract}
An easily detectable chemical marker for the Baccharis dracunculifolia propolis". In the present work a volatile chemical marker (CM) for the Baccharis dracunculifolia $(B d)$ propolis is proposed, which is easily detectable by gas chromatography. It is the most abundant volatile compound in dichloromethane extracts of green propolis from this plant, but it appears also, in different concentrations, in dichloromethane extracts of brown, dark and red propolis from regions where $B d$ grows. The $\mathrm{CM}$ is present in significative concentration in the bud extract of $B d$, in contrast to the leaf extract where its concentration is low. Propolis from regions without $B d$ does not contain the $\mathrm{CM}$. This compound was recently isolated; it is the allyl 3-prenylcinnamate. Commercial samples of green propolis ethanol extract were analyzed and the first quality one (exportation standard) presented the highest concentration on CM. This finding makes easier the quality control of green propolis extracts sold at the market.
\end{abstract}

Keywords: Baccharis dracunculifolia, Asteraceae, propolis, chemical marker.

\section{INTRODUÇ̃̃O}

A própolis é um produto elaborado pelas abelhas com resinas de árvores, cera, pólen, fragmentos de vegetais e secreção própria (Ghisalberti, 1979; Marcucci, 1996). Sua composição química depende, portanto, da flora da região onde é produzida e da época do ano em que é coletada. A própolis do arbusto alecrimdo-campo (Baccharis dracunculifolia), conhecida também como própolis verde, é produzida dos ápices vegetativos desta planta (Bastos, 1998; Oliveira \& Bastos, 1998; Bastos \& Oliveira, 2000; Bankova et al., 1999; Park et al., 2002) que é invasora em várias regiões do Brasil. Entretanto, por razões ainda desconhecidas, esta própolis é produzida fundamentalmente no sul, leste, centro e zona da mata de Minas Gerais, leste de São Paulo, norte do Paraná e em regiões serranas do
Espírito Santo e Rio de Janeiro.

A própolis de alecrim-do-campo constitui, portanto, um produto tipicamente brasileiro e, devido ao fato de ser altamente eficaz no combate a uma série de microrganismos (Bastos, 2001; Park et. al., 2000; Marcucci et al., 2001; Pereira et al., 2002; Ferronatto et al., 2007; Longhini et al., 2007; Packer \& Luz, 2007; Simões et al., 2008), é altamente valorizada no mercado internacional, sendo que, somente no Japão, movimenta um mercado da ordem de setecentos milhões de dólares ao ano (Nascimento, 2005).

É interessante observar que a própolis de alecrim-do-campo possui um teor relativamente baixo de flavonóides, constituintes considerados comumente como responsáveis pelas propriedades terapêuticas de própolis (Pereira et al., 1999).

Embora o chá de alecrim-do-campo pertença à 
medicina popular brasileira há muito tempo e extratos de própolis verdes sejam muito consumidos no Japão, a pesquisa sobre a composição química da própolis verde é relativamente recente, tendo, porém, avançado nos últimos anos, tanto no Brasil (Marcucci et al., 2001; Neto et al., 2002; Pereira et al. 2002; Cunha et al., 2004; Park et al., 2004; Sawaya et al., 2004; Nascimento \& Bezzan, 2001, Nascimento et al., 2003a, 2003b; Vasconcelos, 2006; Sousa et al., 2007; Fabiane et al., 2008) quanto no exterior (Bankova et al. 1999, Midorikawa et al. 2001, Kumazawa et al., 2003, Fukuda et al., 2006).

A análise química da própolis é muito dificultada devido ao fato de se tratar de uma mistura de produtos que varia de acordo com a flora de cada região e da época do ano. Ultimamente, esta análise tem se concentrado nos extratos aquoso e etanólico porque são os mais usados nos diversos tipos de aplicações terapêuticas (Bankova et al. 1999, Kumazawa et al. 2003, Park et al. 2004; Soares et al., 2006; Tavares et al., 2006). A técnica mais utilizada é a cromatografia líquida de alta eficiência (CLAE) acoplada a um detector UV/VIS para detectar as moléculas que estão solubilizadas nestes extratos, principalmente a artepilina $\mathrm{C}$ que é característica de própolis verdes. Entretanto, a aparelhagem requerida é cara, só moléculas que absorvem luz no UV são detectadas e a artepilina $\mathrm{C}$ pode ser determinada juntamente com outras substâncias, prejudicando sua quantificação.

No presente trabalho é apresentado um novo MQ para a própolis de alecrim-do-campo. Foi utilizada a cromatografia gasosa (CG) como ferramenta de trabalho porque moléculas voláteis presentes na própolis trazem informações das plantas visitadas pelas abelhas e esta técnica é muito sensível, simples, rápida e barata. Além disso, estabelecidas as condições de operação, um simples cromatógrafo a gás poderá ser utilizado na quantificação do MQ e, conseqüentemente, para testar a qualidade da própolis verde.

\section{MATERIAL E MÉTODOS}

\section{Origem das amostras}

As amostras de própolis foram coletadas em diversas cidades de Minas Gerais: Santa Bárbara, Perdões, Coromandel, São Gotardo, Nepomuceno, Divinópolis, Betim, Uberlândia, Três Marias, Indianópolis, Tripuí, Ouro Preto e Pelotas (Rio Grande do Sul); os ápices vegetativos e folha de alecrim-docampo foram coletados em Perdões. Todas foram armazenadas a uma temperatura de $-10^{\circ} \mathrm{C}$. As amostras de extrato etanólico comercial de própolis verde foram adquiridas em São Paulo, Belo Horizonte, Divinópolis, e Perdões.

\section{Extratos em diclorometano}

Os extratos em diclorometano foram obtidos dissolvendo-se, em um frasquinho fechado, aproximadamente $0,10 \mathrm{~g}$ de própolis em $1,0 \mathrm{~mL}$ de solvente, por $1 \mathrm{~h}$, com agitação periódica, e filtração com filtro de papel.

\section{Obtenção do óleo essencial dos ápices vegetativos de alecrim}

O óleo essencial dos ápices vegetativos de alecrim foi obtido num aparelho de arraste de vapor de Clevenger. Foram usados cerca de 10,00 g de ápices vegetativos de alecrim e o óleo sobrenadante foi extraído com diclorometano de grau cromatográfico.

\section{Cromatografia gasosa}

A análise de CG do extrato em diclorometano foi feita em um aparelho da marca Shimadzu, modelo GC-17A; coluna capilar DB-5 de $30 \mathrm{~m}, 0,25 \mathrm{~mm}$ de d.i. e $0,25 \mu \mathrm{m}$ de filme; programa de temperatura: $60{ }^{\circ} \mathrm{C}$ - $240{ }^{\circ} \mathrm{C}\left(3{ }^{\circ} \mathrm{C} \mathrm{min}^{-1} \mathrm{e}\right.$ mantida por $\left.20 \mathrm{~min}\right)$; injetor a $220^{\circ} \mathrm{C}$ e detector a $240{ }^{\circ} \mathrm{C}$; pressão da coluna: $135 \mathrm{Kpa}$; fluxo do gás de arraste: $2,2 \mathrm{~mL} / \mathrm{min}$; razão do split 20 ; fluxo total de $50,7 \mathrm{~mL}$; foi usado um detector de massas da mesma marca, modelo QP-5000.

A análise de CG do extrato etanólico comercial foi feita diretamente, ou seja, foi injetado $1 \mu \mathrm{L}$ do extrato no cromatógrafo gasoso acoplado ao espectrômetro de massas. A quantificação se baseou no cromatograma de íons totais (total ions chromatogram, TIC).

\section{RESULTADOS E DISCUSSÃO}

A Figura 1a apresenta o cromatograma do extrato em diclorometano do ápices vegetativos de alecrim-do-campo. $\mathrm{O}$ composto mais abundante indicado pela seta em 39 minutos é o nerolidol. A outra seta destaca o 3-prenilcinamato de alila, de massa molar 256, selecionado como marcador químico (MQ), que corre por volta de 55 minutos.

A Figura $1 \mathrm{~b}$ mostra o cromatograma do extrato em diclorometano da folha de alecrim-do-campo. O composto mais abundante já não é o nerolidol e sim o germacreno-d que corre a 36 minutos e que também está presente no extrato dos ápices vegetativos de alecrim-do-campo, só que em menor concentração. Neste cromatograma é destacado também o composto MQ que no extrato da folha está presente em baixa concentração.

A Figura 1c apresenta o cromatograma do óleo essencial dos ápices vegetativos de alecrim-do-campo. Os compostos em destaque são o nerolidol e o MQ; este se encontra em baixa concentração no óleo essencial.

A Figura 1d mostra o cromatograma do extrato em diclorometano da própolis verde de Santa Bárbara (PSB). O composto mais abundante neste extrato é o 
MQ; o nerolidol é apenas o quarto mais abundante.

A análise da Figura 1 mostra claramente que o cromatograma do extrato em diclorometano da própolis PSB é mais rico em componentes de maior massa que os anteriores, principalmente o do óleo essencial. $\mathrm{Na}$ própolis praticamente não existem os monoterpenos cujo tempo de retenção vai até 25 minutos. Isto é devido à perda de constituintes mais voláteis durante o processo de preparação da própolis pelas abelhas. Outra observação importante que se pode obter da análise da Figura 1 é que o nerolidol se destaca nas quatro amostras, mas na própolis o componente mais proeminente é o MQ que está presente em menores concentrações nos demais extratos.
Há grande concordância na composição dos extratos do ápices vegetativos de alecrim e da própolis PSB, confirmando também pela cromatografia a gás que a fonte vegetal mais importante para a preparação da própolis verde são os ápices vegetativos da Baccharis dracunculifolia.

A Figura 2a-f apresenta os cromatogramas de extratos em diclorometano de algumas própolis verdes mineiras de diferentes procedências. O MQ é destacado por uma seta. A análise das Figuras 1d e 2a-f permite inferir que MQ é o mais abundante em todas as própolis verdes provenientes de regiões onde há alecrim-do-campo. Esse composto tem presença significativa no extrato dos ápices vegetativos de
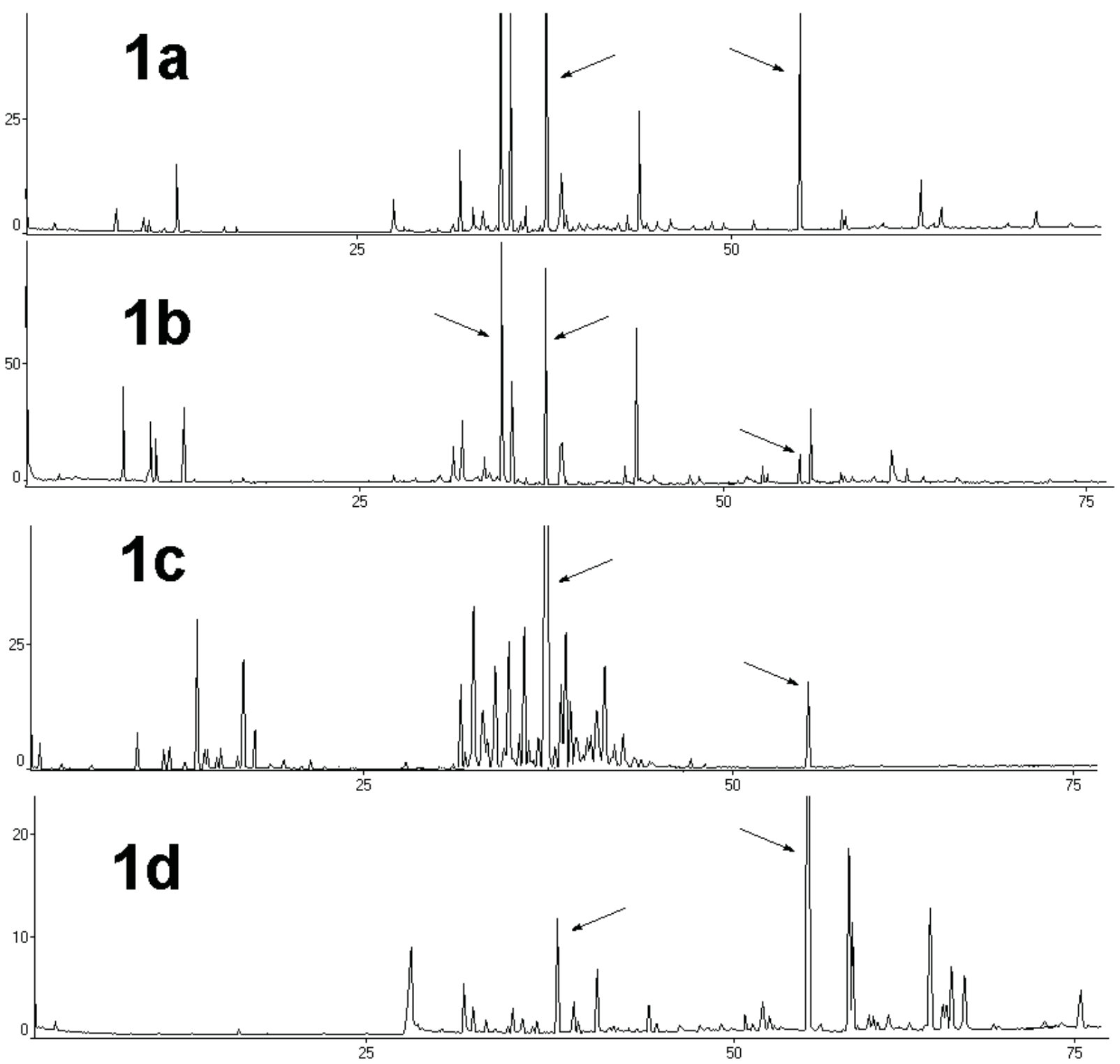

Figura 1. Cromatogramas dos extratos em diclorometano dos ápices vegetativos de alecrim-do-campo- (a), folha de alecrim-docampo (b), óleo essencial do ápices vegetativos de alecrim-do-campo (c) e do extrato em diclorometano da própolis PSB (d). Os compostos destacados por uma seta em 36, 39 e 55 minutos são o germacreno-d, o nerolidol e o MQ, respectivamente. 


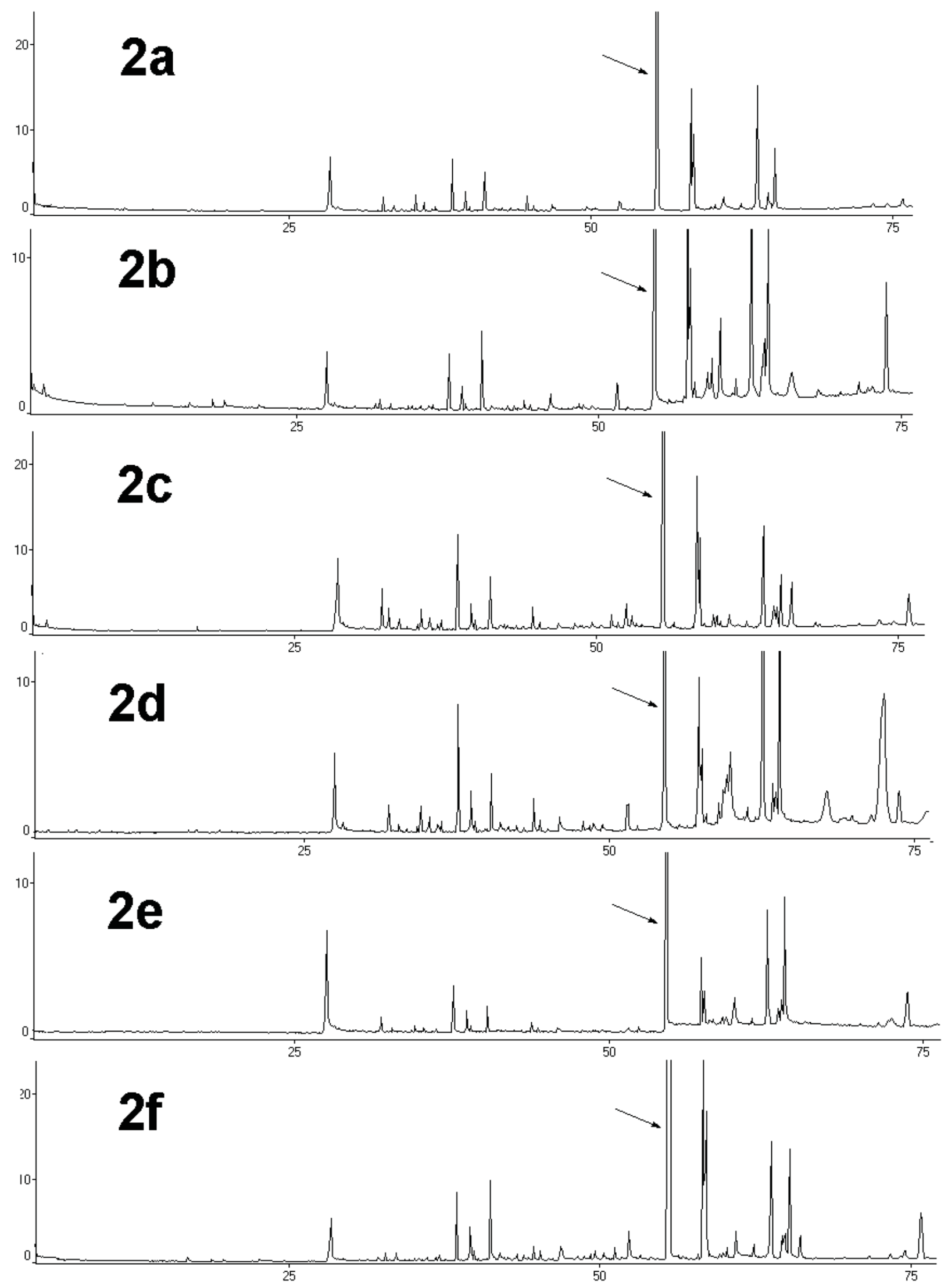

Figura 2. Cromatogramas dos extratos em diclorometano da própolis verde de Perdões (a), própolis verde de Coromandel (b), própolis verde de São Gotardo (c), própolis verde de Nepomuceno (d), própolis verde de Divinópolis (e), própolis verde de Betim (f). O MQ é destacado por uma seta. 


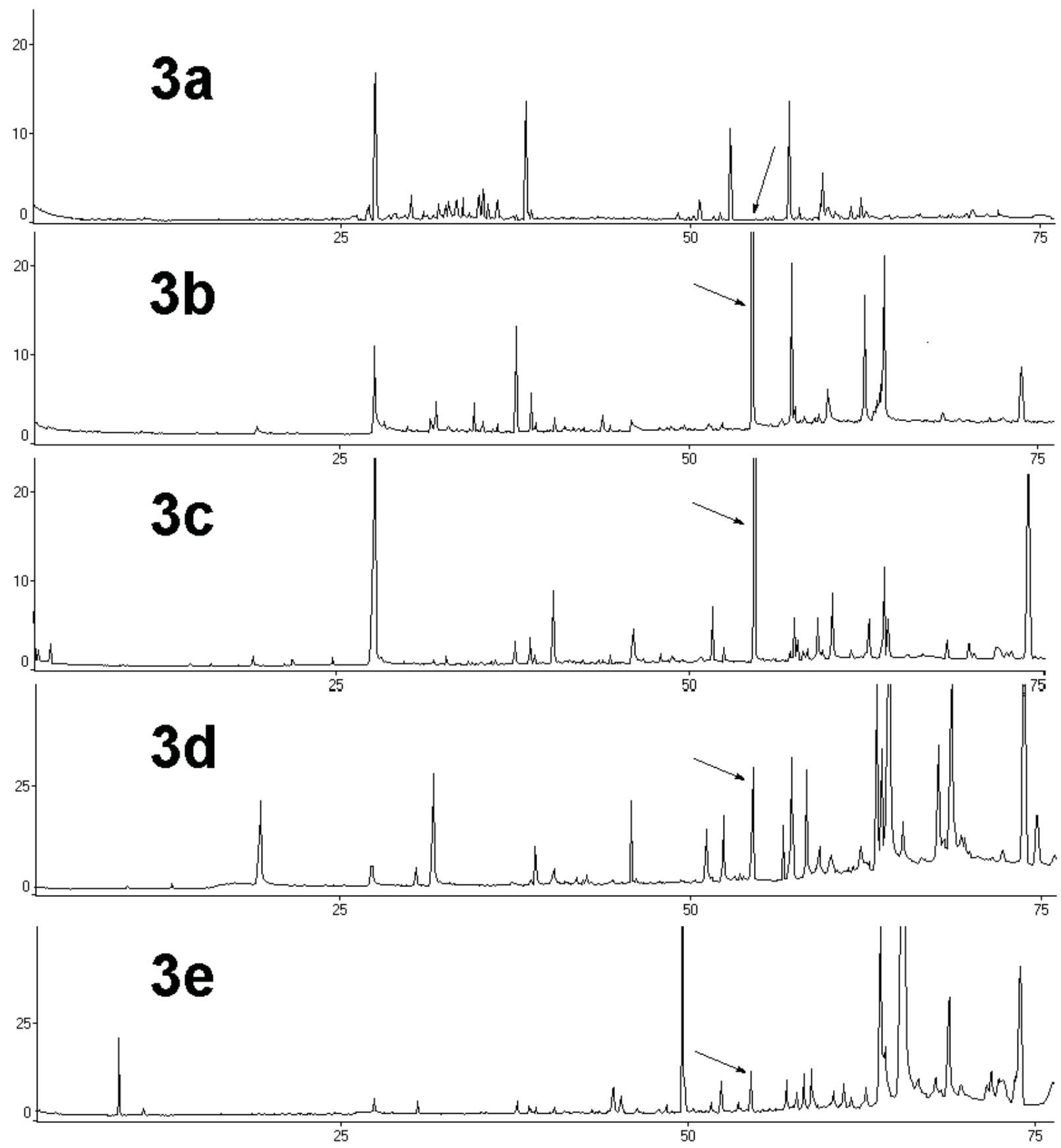

Figura 3. Cromatogramas dos extratos em diclorometano da própolis marrom da região de Bom Jardim, Uberlândia (a), própolis marrom de Coromandel (b), própolis verde-marrom de Três Marias (c), própolis marrom-escura de Indianópolis (d) e própolis marrom-escura de Tripuí (e). O MQ é destacado por uma seta.

alecrim, mas está presente em pequena concentração no extrato em diclorometano das folhas e no óleo essencial do ápices vegetativos desta planta (Figura 1a, 1b, 1c, respectivamente).

A análise dos cromatogramas dos extratos em diclorometano das diferentes própolis verdes (Figuras 1d e 2a-f) permite concluir também que eles são bem parecidos, o que mostra que as abelhas são muito seletivas e que preferencialmente buscam o alecrim-do- campo nas regiões consideradas. $\mathrm{O}$ fato de o $\mathrm{MQ}$ não ser o mais abundante no extrato em diclorometano do alecrim-do-campo e sim nos extratos em diclorometano das própolis verdes sugere que, durante o processo de elaboração da própolis pelas abelhas, substâncias como o nerolidol, o germacreno-d, entre outras, são parcialmente decompostas ou volatilizadas.

A Figura 3a-e apresenta os cromatogramas de amostras de própolis não-verdes de diferentes 


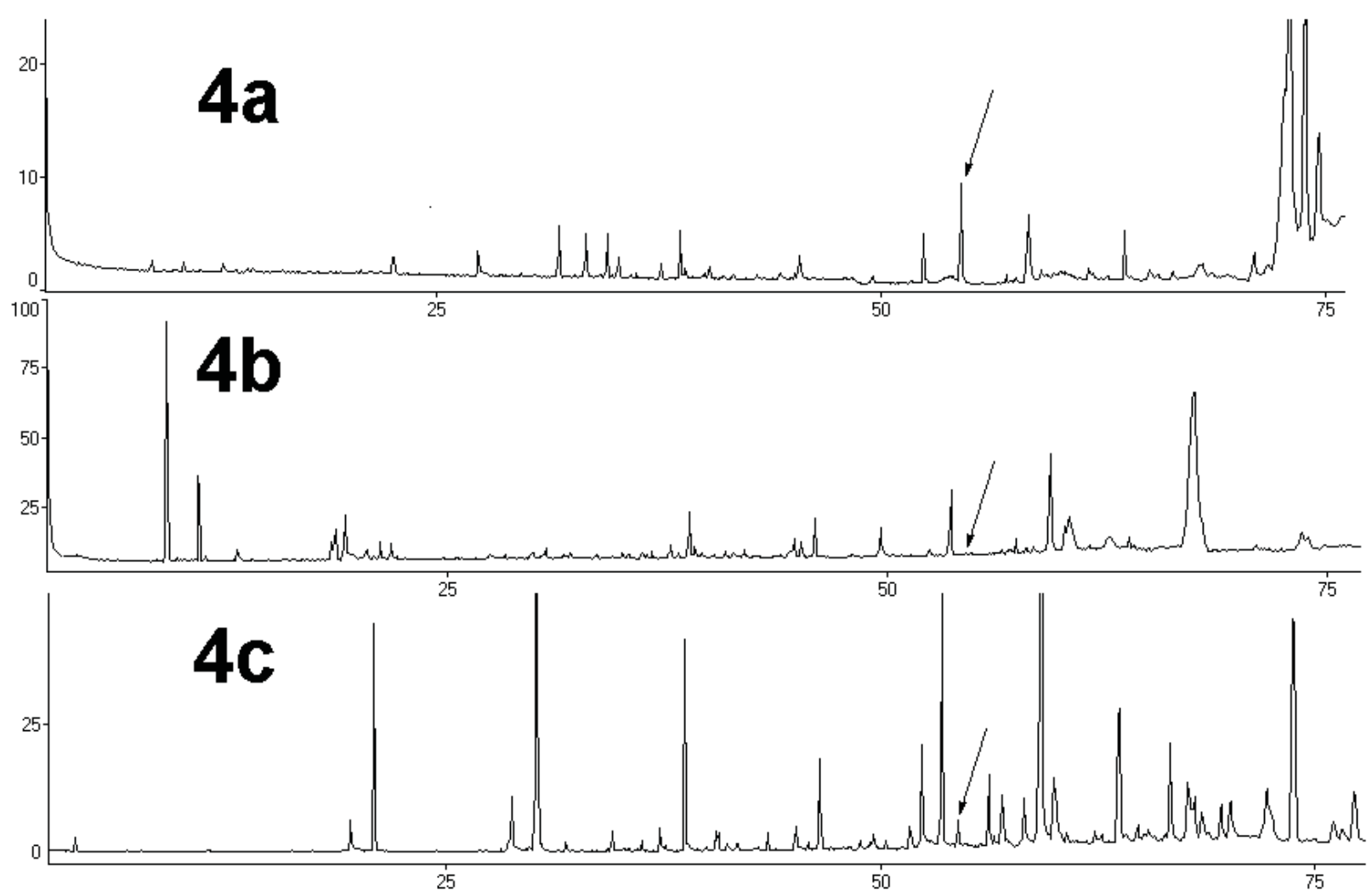

Figura 4. Cromatograma dos extratos em diclorometano da própolis preta de Ouro Preto (a), própolis do Rio Grande do Sul (b), própolis avermelhada de Coromandel (c). O MQ é destacado por uma seta.

procedências. Os cromatogramas mostram que o MQ está ausente na própolis marrom de Uberlândia (proveniente de um pasto apícola sem alecrim) e continua presente em própolis de regiões que contêm alecrim, embora a própolis não seja a verde. Mais ainda, a concentração de MQ na própolis marrom de Coromandel e na verdemarrom de Três Marias é tão alta ou maior do que em algumas própolis verdes. Este resultado é surpreendente porquanto se supunha que própolis que contivessem alecrim-do-campo fossem sempre verdes. Certamente que resinas ou vegetais de coloração marrom do local atraíram também as abelhas. A presença de mais de 10\% de fragmentos vegetais de outras fontes é suficiente para mudar a coloração da própolis verde, talvez devido à forma diferente de como as resinas foram coletadas nestas plantas ou à interação entre estas resinas ou à degradação ou à coloração diferente desses vegetais. Este tipo de própolis foi denominado de constituição mista (Bastos, 1998; Oliveira \& Bastos, 1998; Bastos \& Oliveira, 2000).

Outras amostras de própolis preta, amarela e vermelha, provenientes de região ricas em alecrim, apresentaram também o MQ, e a própolis de Pelotas, Rio Grande do Sul (região sem alecrim) não apresentou o MQ (Figura 4a-c).

Os resultados apresentados acima mostram que as própolis de locais que contêm alecrim-do-campo possuem um marcador químico MQ. Este marcador químico foi recentemente isolado do extrato clorofórmico da própolis verde e se trata do 3-prenilcinamato de alila (Negri et al., 2003), mostrado na Figura 5.

A Tabela 1 apresenta os resultados da análise de alguns extratos etanólicos de própolis verde vendidos comercialmente e de outro extrato de própolis não-verde (proveniente de Uberlândia). O extrato de Perdões foi preparado com própolis de exportação (ultraverde) e o de Divinópolis com própolis verde comum. Verifica-se que a concentração do MQ no extrato de Divinópolis é menor do que no extrato de Perdões. Mais ainda, a concentração do MQ nos extratos e São Paulo e Belo Horizonte indica que estes extratos foram preparados com própolis verde e outra(s) não verde(s). O extrato da própolis de Uberlândia não continha o $\mathrm{MQ}$, como era de se esperar.

Este descoberta é muito importante porque possibilita um controle rápido e eficaz diretamente de extratos comerciais de própolis verde, coibindo falsificações que já estão ocorrendo.

\section{CONCLUSÕES}

O composto volátil mais abundante do extrato em diclorometano de própolis verdes é o 3-prenilcinamato de alila que é facilmente detetável via cromatografia gasosa e pode servir como marcador químico deste tipo de própolis. Ele tem um tempo de 


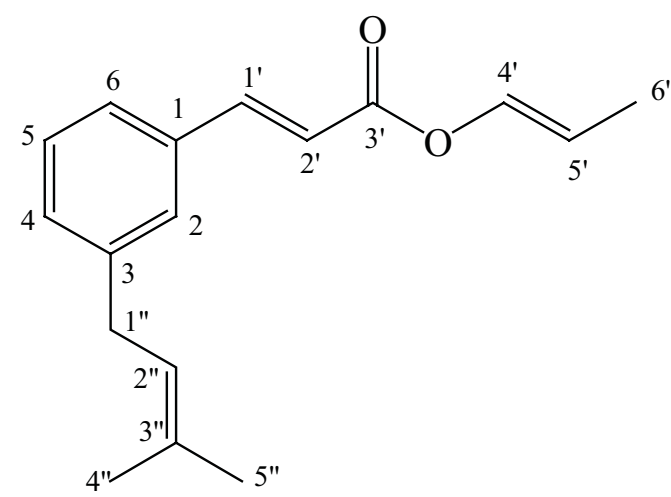

Figura 5. Estrutura do 3-prenilcinamato de alila.

Tabela 1. Concentração do MQ em algumas amostras de própolis.

\begin{tabular}{lc}
\hline Tipo de própolis & Concentração do MQ (\% TIC) \\
\hline Perdões (ultraverde) & 26,61 \\
Divinópolis (verde comum) & 22,27 \\
Belo Horizonte & 16,59 \\
São Paulo & 16,10 \\
Uberlândia (marrom) & 0,00
\end{tabular}

retenção de 55 minutos, nas condições empregadas na análise cromatográfica deste trabalho.

A determinação da concentração do 3-prenilcinamato de alila em extratos de própolis verdes de alecrim, via cromatografia a gás, constitui uma maneira rápida e eficaz para controle de qualidade desses produtos no mercado.

Amostras de própolis marrons, preta e vermelha, provenientes de regiões onde há alecrimdo-campo, contêm também o 3-prenilcinamato de alila em diferentes concentrações, segundo a abundância de alecrim-do-campo na região, sendo que algumas delas possuem maior concentração do marcador químico do que a própria própolis verde. Este dado é importante porque essas própolis são consideradas de segunda qualidade.

\section{AGRADECIMENTOS}

A Dra. E. M. Bastos (FUNED - BH), pelas amostras de própolis marrom de Tripuí e preta de Ouro Preto e sugestões; aos Apiários Mackllani (Santa Bárbara), Girassol e Santa Rita (Uberlândia), Alecrim Dourado (Perdões), Naturapis (Divinópolis) e Cia da Abelha (Contagem) e aos apicultores Ana Paula Veiga (Nepomuceno), João Batista de Almeida (Carrancas), Júnior Reis Souto (Coromandel), pelas outras amostras de própolis. Ao CNPq pelas bolsas de mestrado (D. C. Reis) e de produtividade em pesquisa (D. P. Veloso).

\section{REFERENCIAS}

Bankova V, Krasteva GB, Sforcin JM, Frete X, Kujumgieev A, Rodella RM, Popov S 1999. Phytochemical evidence for the plant origin of Brazilian propolis from São Paulo State. Z Naturforsc 54c: 401-405.

Bastos EMAF 1998. Indicadores de la calidad y del origen botanico del propóleo producido por abejas Apis mellifera en áreas del cerrado del Estado de Minas Gerais. VI Congresso Ibero-Americano de Apicultura. Mérida, México.

Bastos EMAF, Oliveira VDC, Soares AEE 2000. Microscopic characterization of the green proplis, produced in Minas Gerais State, Brazil, Honeybee Sci 21: 179180.

Bastos EMAF 2001 Origem botânica e indicadores de qualidade da própolis verde produzida no Estado de Minas Gerais. Ribeirão Preto, 137p. Tese de Doutorado - Ribeirão Preto: USP/FFCL.

Cunha IBS, Sawaya ACHF, Caetano FM, Shimizu MT, Marcucci MC, Drezza FT, Povia GS, Carvalho PGO 2004. Factors that influence the yield and composition of Brazilian propolis extracts. J Braz Chem Soc.15: 964-970.

Fabiane KC, Ferronatto R, Santos AC, Onofre SB 2008. Physicochemical characteristics of the essential oils of Baccharis dracunculifolia and Baccharis uncinella D.C. (Asteraceae). Rev Bras Farmacogn 18: 197-203.

Ferronatto R, Marchesan ED, Pezenti E, Bednarski F, Onofre SB 2007. Atividade antimicrobiana de óleos essenciais produzidos por Baccharis dracunculifolia D.C. e Baccharis uncinella D.C. (Asteraceae). Rev Bras Farmacogn 17: 224-230.

Fukuda M, Ohkoshi E, Makino M, Fujimoto Y 2006. Studies on the constituents of the leaves of Baccharis Dracunculifolia (Asteraceae) and their cytotoxic activity. Chem Pharm Bull 54: 1465-1468.

Ghisalberti EL 1979. Propolis: a review. Bee World 60: 5984.

Kumazawa S, Yoneda M, Shibata I, Kanaeda J, Hamasaka T, Nakayama T 2003. Direct evidence for the plant origin of Brazilian propolis by the observation of honeybee behavior and phytochemical analysis. Chem Pharm Bull 51: 740-742.

Longhini R, Raksa SM, Oliveira ACP, Svidzinski TIE, Franco SL 2007. Obtenção de extratos de própolis sob diferentes condições e avaliação de sua atividade antifúngica. Rev Bras Farmacogn 17: 388-395.

Marcucci MC 1996. Propriedades biológicas e farmacêuticas dos constituintes da própolis. Quim Nova 19: 529536.

Marcucci MC, Ferreres FGC, Bankova VS, Castro SL, Dantas AP, Valente PHM, Paulino N 2001. Phenolic compounds from Brazilian propolis with pharmacological activities. J Ethnopharmacol 74: 105-112.

Midorikawa K, Banskota AH, Tezuka Y, Nagaoka T, Matsushige K, Message D, Huertas AAG, Kadota S 2001. Liquid chromatography-mass spectrometry analysis of propols. Phytochem Anal 12: 366-373.

Nascimento EA, Bezzan LCF 2001. Estudo da própolis do Triângulo Mineiro. Parte 1: Identificação dos 
constituintes solúveis em metanol/acetato de etila por CG/EM, Mensagem Doce 63: 7-15.

Nascimento EA, Morais SAL, Bezzan LCF, Chang R, PilóVeloso D 2003a. Análise do resíduo insolúvel de uma própolis do Triângulo Mineiro. Rev Soc Bras Cienc Tecnol Alim 37s: 84-87.

Nascimento EA, Morais SAL, Bezzan LCF, Chang R, Vallejo MCG 2003b. Comparação entre os constituintes da própolis e da resina de eucaliptos provenientes do cerrado. Cienc Eng 12: 15-18.

Nascimento AVJ 2005. Própolis Verde - Produção, Mercado, Tendências e Padronização. Primeiro Seminário Apícola sobre Própolis Verde. Muzambinho, Brasil.

Negri G, Salatino MLF, Salatino A 2003. Green propolis: unreported constituents and a novel compound from chloroform extracts. J Apicult Res 42: 39-41.

Neto FRA, Pereira AS, Nascimento EA 2002. Lupeol alkanoates in Brazilian propolis. Z Naturforsch $57 c$ : 721-726.

Oliveira VDC, Bastos EM 1998. Aspectos morfo-anatômicos da folha de Baccharis dracunculifolia DC. (Asteraceae) visando a identificação da origem botânica da própolis. Acta Bot Bras 12: 431-439.

Packer JF, Luz MMS 2007. Método para avaliação e pesquisa da atividade antimicrobiana de produtos de origem natural. Rev Bras Farmacogn 17: 102-107.

Park YK, Ikegaki M, Alencar SM, Moura FF 2000. Evaluation of Brazilian propolis by both physicochemical methods and biological activity. Honeybee Sci 21: 85-90.

Park YK, Alencar SM, Aguiar CL 2002. Botanical origin and chemical composition of Brazilian propolis. $\mathrm{J} \mathrm{Agr}$ Food Chem 50: 2502-2506.

Park YK, Paredez-Guzman JF, Aguiar CL, Alencar SM, Fujiwara FY 2004. Chemical constituents in Baccharis dracunculifolia as the main botanical origin of southeastern Brazilian propolis. J Agr Food Chem 52: 1100-1103.

Pereira AS, Ramos MFS, Poças ESC, Dias PCM, Santos EP, Silva JFM, Cardoso JN, Neto FRA 1999. Study of propolis by High Temperature High Resolution Gas Chromatography-Mass Spectrometry. Z Naturforsch $54 c: 395-400$.

Pereira AS, Seixas FRMS, Neto FRA 2002. Própolis: 100 anos de pesquisa e suas perspectivas futuras. Quim Nova 25: 321-326.

Sawaya ACHF, Tomazela DM, Cunha IBS, Bankova VS, Marcucci MC, Custódio AR, Eberlin MN 2004. Electrospray ionization mass spectrometry fingerprinting of propolis. Analyst 129: 739-744.

Simões CC, Araújo DB, Araújo RPC 2008. Estudo in vitro e ex vivo da ação de diferentes concentrações de extratos de própolis frente aos microrganismos presentes na saliva de humanos. Rev Bras Farmacogn 18: 84-89.

Soares AKA, Carmo GC, Quental DP, Nascimento DF, Bezerra FAF, Moraes MO, Moraes MEA 2006. Avaliação da segurança clínica de um fitoterápico contendo Mikania glomerata, Grindelia robusta, Copaifera officinalis, Myroxylon toluifera, Nasturtium officinale, própolis e mel em voluntários saudáveis. Rev Bras Farmacogn 16: 447-454.

Sousa JPB, Furtado NAJC, Jorge R, Soares AEE, Bastos JK 2007. Perfis físico-químico e cromatográfico de amostras de própolis produzidas nas microrregiões de Franca (SP) e Passos (MG), Brasil. Rev Bras Farmacogn 17: 85-93.

Tavares JP, Martins IL, Vieira AS, Lima FAV, Bezerra FAF, Moraes MO, Moraes MEA 2006. Estudo de toxicologia clínica de um fitoterápico a base de associações de plantas, mel e própolis. Rev Bras Farmacogn 16: 350-356.

Vasconcelos Y 2006. Própolis contra câncer. Revista Pesquisa da FAPESP 129: 72-74. 